\title{
ACQUIRED DYSARTHRIA WITHIN THE CONTEXT OF THE FOUR-LEVEL FRAMEWORK OF SPEECH SENSORIMOTOR CONTROL
}

\author{
Alexandra Stipinovich and Anita van der Merwe
}

\author{
Department of Communication Pathology \\ University of Pretoria
}

\begin{abstract}
The Four-Level Framework of speech sensorimotor control (Van der Merwe, 1997) complicates the traditional view of dysarthria as a purely motor execution disorder. According to this framework, hypokinetic, hyperkinetic and ataxic dysarthria are programming-execution dysarthrias, while flaccid dysarthria is the only execution dysarthria. This preliminary study aimed to differentiate programming-execution dysarthria from execution dysarthria by examining variability of the temporal control of speech. Six participants and five control participants repeated 15 stimulus words ten times. Voice onset time, vowel duration, vowel steady state duration and vowel formant transition duration were measured acoustically. The coefficient of variation of the temporal parameters, and the correlation coefficient between the durational parameters, were calculated and analysed using descriptive statistics. The coefficient of variation revealed that the speakers with dysarthria were more variable than the control speakers. All participants, except those with flaccid dysarthria, showed similar patterns of intra-subject variability. Those with flaccid dysarthria exhibited greater intra-subject variability of voice onset time. The correlation analysis did not reveal differences between dysarthria type, or between the dysarthric speakers and the controls. Differences found in the patterns of variability may support the hypothesis that individuals with programming-execution dysarthria resort to a different level of control than those with execution dysarthria. Further research in this field is necessary.
\end{abstract}

Key Words: flaccid dysarthria, hypokinetic dysarthria, ataxic dysarthria, temporal variability, motor programming, motor execution, Four-Level Framework of speech sensorimotor control.

\section{INTRODUCTION}

The traditional classification of dysarthria as a motor execution disorder (Darley, Aronson \& Brown, 1975) is challenged by recent advances in theoretical models of the sensorimotor control of speech. One such model is the FLF of speech sensorimotor control (Van der Merwe, 1997; 2007). This framework has recently been described as 'possibly the most detailed and comprehensive attempt to explain impairments in the speech production process, relating sub-components to underlying neural structures, diagnosis of motor speech disorders, and principled development of treatment strategies for such disorders' (Ballard, Granier \& Robin, 2000 p. 972). According to the FLF (Van der Merwe, 1997; 2007), neural structures such as the basal ganglia (implicated in hypokinetic and hyperkinetic dysarthria), and the lateral cerebellum (implicated in ataxic dysarthria), are involved in both the programming of movements and the execution of movements. Areas of the cerebellum other than the lateral cerebellum, as well as the lower motor neurons, are involved in motor execution. Dysarthrias associated with damage to the basal ganglia or lateral cerebellum are thus likely to show signs of both programming and execution difficulties and may therefore exhibit similar trends that would differentiate them from pure motor execution disorders. Thus, when viewed within the context of the FLF (Van der Merwe, 1997; 2007), the traditional classification of dysarthria as a disorder of motor execution may need to be revised. In a recent publication, Duffy and Kent (2001) acknowledged the challenges that the FLF (Van der Merwe, 1997) poses to future research and the classification of dysarthria.

Models based on the normal process of language and speech production should guide the classification and understanding of the underlying nature of communication disorders. Until recently, the most accepted model of speech production has been a three-level model proposed by various authors (e.g.
Darley et al., 1975; Itoh \& Sasanuma, 1984). The origin of this three-level model may be traced back to the three hierarchical stages involved in motor skill, namely the planning (encoding), programming and execution of movements (Brooks, 1986; Magill, 2007). While speech production is a motor act and therefore likely to entail the same phases of motor planning, programming and execution as other forms of movement, verbal communication also entails the linguistic planning of the utterance to be made. A pre-motor phase therefore needs to be distinguished from the three motor phases of planning, programming and execution. According to Van der Merwe (1997), linguistic planning is equated with motor planning for speech by the three-level model of speech production. This lack of differentiation between linguistic planning and the three phases involved in the preparation and production of the speech act has led to an inadequate formulation of the true nature of the motor planning, motor programming and execution of speech (Van der Merwe, 1997). In view of the above-mentioned limitations of the three-level model, Van der Merwe proposed the FLF of speech sensorimotor control in 1997. This framework consists of one pre-motor stage, namely linguistic-symbolic planning, and three motor stages, namely motor planning, motor programming and motor execution. According to the FLF (Van der Merwe, 1997; 2007), aphasia constitutes a breakdown in linguistic-symbolic planning. Apraxia of speech is considered to reflect a breakdown primarily in speech motor planning, although motor programming may also be compromised. The dysarthrias constitute a breakdown in programming and execution, or in execution only (Van der Merwe, 1997; 2007).

According to the FLF (Van der Merwe, 1997; 2007), a coalition of neural structures is involved in the control of verbal communication, many of which are active during more than one stage of processing. For example, the temporal-parietal areas and Broca's area are involved in linguistic-symbolic planning. Broca's area, together with other cortical motor ar- 
eas, is also involved in speech motor planning. Furthermore, speech motor programming is controlled by the basal ganglia, the lateral cerebellum, the supplementary motor area (SMA), the motor cortex and the fronto-limbic system. However, the cerebellum, SMA and basal ganglia are also involved in the control of speech execution (Van der Merwe, 1997). This coinvolvement of neural structures on more than one level of processing complicates the accurate differentiation of breakdown on the various levels. The current study is a first attempt to differentiate between disorders on both a speech motor programming and execution level, from disorders in speech execution only.

Given the above description of the involvement of neural structures such as the basal ganglia and lateral cerebellum in both the programming and execution of speech movements, the possibility of dual symptomatology in dysarthrias such as hypokinetic dysarthria and ataxic dysarthria is strong. Only those dysarthrias caused by damage to the areas of the cerebellum other than the lateral cerebellum, as well as due to lower motor neuron disorders, are seen to display pure deficits in motor execution and are termed flaccid dysarthria (Van der Merwe, 1997). Hypokinetic dysarthria and ataxic dysarthria may therefore constitute programming-execution dysarthrias, while flaccid dysarthria may constitute execution dysarthria.

Motor programming for speech is defined in the FLF (Van der Merwe, 1997; 2007) as the specification and sequencing of motor programmes for the movements of the muscles of the articulatory structures. Motor programmes specify muscle tone, velocity, direction and range of movement (Brooks, 1986). According to the FLF (Van der Merwe, 1997; 2007), a disorder at the level of motor programming would result in the impairment of muscle tone, velocity, direction and range of movements. The repeated initiation and feed-forward of cooccurring and successive motor programmes to the lower motor centers would also be impaired. Speech symptoms associated with such deficits may include sound distortion, abnormalities in speech rate, and/or problems with the initiation of movements for speech. Motor programming difficulties may occur in the absence of hypo- or hypertonia or involuntary movements which are traditionally associated with dysarthria and which cause the breakdown in execution (Van der Merwe, 1997; 2007).

The execution of movement is mediated at the lowest level of the motor hierarchy and is set in motion by subprogrammes that are conveyed from the middle levels to the lower motor centres, namely the spinal levels (Brooks, 1986). Flaccid paralysis is caused by damage to the nuclei, the axons or the neuromuscular junctions that make up the lower motor neuron (Duffy, 2005). All signals to produce movement arising in the central nervous system must pass through the final common pathway (which includes the lower motor neuron). As a result, all types of movement (voluntary, automatic and reflexive) are impaired in the case of motor execution difficulties (Hageman, 1997).

Four issues complicate the differentiation between the signs associated with a pure motor execution disorder and a programming-execution disorder. Firstly, it is to be expected that all types of dysarthria (flaccid, spastic, ataxic etc.) will differ in terms of their signs and speech motor characteristics as the underlying nature of the associated neuromotor disorder and its effect on muscle tone and movement characteristics differs. Secondly, there is likely to be some similarity between the signs and motor speech characteristics of the different types of dysarthria as velocity, direction and range of movements are affected to some degree in all types of dysarthria. Thirdly, the possibility of certain motor characteristics, such as spasticity, masking a programming disorder must also be taken into account when attempting to differentiate between a pure execution difficulty and a programming-execution difficulty (Van der Merwe, 1997). Finally, the study of neuromotor speech disorders is complicated by the interaction of motor impairment and motor control compensations in response to that impairment (Kent, Netsell \& Abbs, 1991). Symptoms of dysarthric speech may thus not solely reflect the role of the disordered neurological area in the regulation of speech, but also what the speech motor control system can do in the face of such damage. Signs exhibited by dysarthric speakers may thus be the result of compensatory techniques that have involved the adjustment of motor programmes (Hixon, Putnam \& Sharp, 1983). From the above discussion it is clear that, to differentiate between a speech motor programming-execution disorder and a speech motor execution disorder, an index or parameter of motor control, which will reveal any possible differences between these two types of dysarthria, needs to be identified.

Variability of motor speech performance is frequently regarded as a key to the nature of the speech disturbance (Seddoh, Robin, Sim, Hageman, Moon \& Folkins, 1996). According to McHenry (2004), the implications of variability for speech production are not yet clear. For example, the complexity of most skilled behaviours requires the ability to accomplish a goal in different ways. This capacity of a motor system to accomplish the same final product despite considerable variation in the individual components is referred to as motor equivalence (Hughes \& Abbs in Abbs, 1986). However, should the variation within the individual components exceed the boundaries of equivalence, the end product will be speech that is perceived as unstable or inconsistent and distorted (Van der Merwe, 1997). Thus, on the one hand, variability may reflect inherent flexibility of a motor system. On the other hand, temporal variability in motor performance is seen to suggest instability in motor control (e.g. Gerratt, 1983; McHenry, 2004; Munhall, 1989; Seddoh et al., 1996). If the latter is true, then the nature of variability of the temporal control of speech may reveal the underlying motor control disorder.

Acoustic and physiological investigations have suggested that in communicatively impaired individuals, disruptions in temporal control reflect a disrupted motor control system (Duffy, 2005; Seddoh et al., 1996). Temporal aspects of speech include voice onset time, vowel duration, vowel steady state duration, vowel formant transition duration, and speech rate. All of these are potential sources of variation in speech (Forest \& Weismer, 1997; Pols, 1986). Vowel duration and vowel steady state duration may be representative of what Levelt (1989) refers to as intrinsic timing. According to Levelt (1989), "segment durations are in some way globally specified' (p. 442) and 'such syllable-specific durational properties are part of the stored syllable program' (p. 442). Intrinsic duration is thus determined before execution starts, when viewed within the context of the FLF (Van der Merwe, 1997; 2007). Levelt (1989) also distinguishes extrinsic timing. According to Levelt (1989, p.436), 'the duration of moving from one phonetic target to the next depends only on the mechanical properties of the musculature involved', i.e. on executive factors beyond the phonetic plan. When viewed within the context of the FLF (Van der Merwe, 1997; 2007), vowel steady state duration and vowel duration may be determined by the planning and programming levels while vowel formant transition duration (extrinsic timing) may be determined on the execution level. Due to the possible differential breakdown in the durational parameters of vowels, both these aspects of duration were ex- 
amined in this study.

Voice onset time is an index of the temporal coordination of the movements of the vocal folds and the oral structures and thus reflects interarticulatory synchronization (Van der Merwe, 1997). Increased variability of voice onset time may reflect a disruption of this aspect of temporal control of speech movements and was therefore also examined in this study. According to the FLF (Van der Merwe, 1997; 2007), the potential for interarticulatory synchronization is created on the motor planning level of the speech production process, before motor programming and execution occur. Although abnormalities of VOT may result from disorders of planning, programming and execution, the possibility exists that the nature of the disturbance of VOT may differ for the different types of dysarthria.

In describing variability of movement, the form or type of variability must be taken into account in addition to the amount or magnitude of variability (Munhall, 1989). For skilled activities, such as speech, there must be some stability in the internal timing relations between the muscle events that underlie the phonetic percept (Harris, Tuller \& Kelso, 1986). The nature of the correlation between the durational parameters may reflect the speaker's ability to maintain the internal timing relations between the durational parameters in order to achieve accurate production of the target words. Thus, in addition to measuring the degree of variability of the above temporal parameters, the correlation between the durational parameters was also calculated.

Variability of motor speech control has been examined in different types of dysarthria. For example, according to Hertrich and Ackerman (1999), individuals with ataxic dysarthria are expected to exhibit increased variability of target positions and segmental durations. According to Reed and Franks (1998), individuals with Parkinson's Disease (and associated hypokinetic dysarthria) display increased on-line adjustments to movement as movement complexity increases, leading to increased variability in motor performance. Turner and Tjaden (2000) found that individuals with spastic-flaccid dysarthria caused by Amyotrophic Lateral Sclerosis (ALS) display longer and more variable vowel durations than normal speakers. Previous research has also established that variability of speech production depends on the severity of the dysarthria under investigation (McHenry, 2003). However, despite previous research into the variability of the temporal control of speech exhibited by individuals with dysarthria, the nature of these differences has not been compared across the different dysarthria types. This is a preliminary study, which aimed to differentiate between programming-execution dysarthria and execution dysarthria by examining variability of the temporal control of speech. Different patterns of temporal control errors exhibited by the participants with programming-execution dysarthria as opposed to the participants with execution dysarthria may strengthen the hypothesis presented by the FLF (Van der Merwe, 1997; 2007) that programming-execution dysarthria should be differentiated from pure execution dysarthria. On the other hand, similar patterns of errors for the different dyarthrias under investigation may suggest that the level of impairment contributing to the timing disturbance in the three populations is the same.

\section{METHOD}

\section{Aims}

The aim of this study was to examine the variability of temporal parameters during speech production of participants with flaccid dysarthria, representative of execution dysarthria, and participants with hypokinetic dysarthria and ataxic dysarthria, representative of programming-execution dysarthria.

The following sub-aims were formulated to facilitate achievement of the main aim of this study:

- to determine and compare the degree of variability of the temporal control of voice onset time (VOT) as well as the durational parameters of vowel duration (VD), vowel steady state duration (VSSD), and vowel formant transition duration (VFTD) of the speech of participants with flaccid dysarthria, hypokinetic dysarthria and ataxic dysarthria and their matched control participants across repeated production of stimulus words

- to determine and compare the nature of the correlation between the durational parameters (VD, VSSD, VFTD) exhibited by participants with flaccid dysarthria, hypokinetic dysarthria, ataxic dysarthria and their matched control participants across repeated production of the stimulus words as an index to the nature of the internal timing relations between the durational parameters

\section{Research Design}

A descriptive, non-experimental quantitative research design was selected for this study (Leedy, 1997). This type of research involves making careful descriptions of observed phenomena, as well as the exploration of possible relationships between these phenomena (Leedy, 1997). In achieving the first sub-aim of the study, the focus of observation was on the variability of the temporal parameters of speech. In the second sub-aim, the extent to which differences in one durational parameter (e.g. duration of VSSD) were related to differences in another durational parameter was determined.

\section{Participants}

The participants were required to present with acquired flaccid dysarthria, hypokinetic dysarthria or ataxic dysarthria. The locus of the disease or damage was to be restricted to a single neurological structure so that the results obtained would reflect the pathology under investigation. The disease process displayed by each participant was required to have been diagnosed by a neurologist and the presence of dysarthria confirmed by a qualified speech-language therapist experienced in the field of neuromotor speech disorders. The minimum and maximum age criteria were based on the processes related to the effects of age on the motor performance. The minimum age criterion was set at 18 years. A maximum age criterion of 75 years was set. This study was not confined to members of a specific gender. The participants were required to be either first-language English or Afrikaans speakers as these are the languages in which the researcher is proficient. The participants were required to have no abnormalities of the oral-facial structures other than those associated with the disease process responsible for dysarthria. All participants were to have a negative history of previous neurological, respiratory, speech or voice disorders. All participants were required to present with adequate comprehension, as determined through spontaneous conversation, so as to understand the instructions given, as well as adequate vision so as to be able to read the target phrases.

Six individuals were selected, by means of nonprobability sampling (Leedy \& Ormrod, 2005) to participate in this study. The sample was confined to six participants owing to the limited availability of individuals with pure ataxic, hypokinetic or flaccid dysarthria; and also due to the detailed data 
collection and analysis procedures followed. The participants are referred to as FD1, FD2, HD1, HD2, AD1 and AD2, respectively; where $\mathrm{FD}$ refers to flaccid dysarthria, $\mathrm{AD}$ to ataxic dysarthria and HD to hypokinetic dysarthria. A description of the participants is provided in Table 1 . 1ncluded in Table 1 is a description of the perceptual speech characteristics of each participant and an indication of which participant from each dysarthria group presented perceptually with the more severe dysarthria. As indicated in Table 1, Participant FD1 was diagnosed with Amyotrophic Lateral Sclerosis (ALS). ALS is a form of Motor Neuron Disease and is associated with damage to the upper motor neurons and lower motor neurons, typically resulting in a mixed form of dysarthria with bulbar (flaccid) and pseudobulbar (spastic) features (Duffy, 2005). Participant FD1 was included in this study as he presented with predominantly lower motor neuron signs. The muscle tone of Participant FD1's speech structures was reduced and he exhibited decreased reflexes. The mixed nature of ALS was, however, taken into consideration during the interpretation of results.
Not one of the participants was receiving speech therapy at the time of data collection. Each participant was asked to list the medications he or she was taking as well as the dosage thereof. The possible side-effects of this medication were taken into account in the interpretation of the results.

Five matched control participants were used to control for the effects of age, gender and language. The control participants presented with perceptually normal speech, no structural or functional abnormalities of the oral-facial structures, and no history of neurological, respiratory, speech, hearing and voice problems. The controls are referred to as CFD1, CFD2, CHD1, CHD2, CAD1 and CAD2. CFD1 and CHD1 is the same person as he could be matched with both Participant FD1 and Participant HD1. The matching of one control participant to two participants was not deemed problematic, as in no instances were the results of the participants or control participants grouped together. Instead, the performance of each of the participant was compared to that of a matched control.

Table 1: Description of participants

\begin{tabular}{|c|c|c|c|c|c|c|}
\hline & FD1 & FD2 & HD1 & $\mathrm{HD2}$ & AD1 & AD2 \\
\hline Etiology & $\begin{array}{l}\text { Amyotrophic Lat- } \\
\text { eral Sclerosis }\end{array}$ & $\begin{array}{l}\text { Ideopathic atrophy of lower } \\
\text { motor neuron } \mathrm{N} \text { XII and NX}\end{array}$ & $\begin{array}{l}\text { Ideopathic Parkin- } \\
\text { son's Disease }\end{array}$ & $\begin{array}{l}\text { Post-encephalitic } \\
\text { Parkinson's Dis- } \\
\text { ease }\end{array}$ & $\begin{array}{l}\text { Assault to head } \\
\text { with damage to } \\
\text { cerebellum. }\end{array}$ & $\begin{array}{l}\text { Gunshot } \\
\text { wound: occipi- } \\
\text { tal and cerebel- } \\
\text { lar atrophy. }\end{array}$ \\
\hline Age & 72 years & 73 years & 81 years & 67 years & 20 years & 39 years \\
\hline Age at onset & 64 years & 72 years & 68 years & 55 years & 19 years & 38 years \\
\hline Gender & Male & Male & Male & Female & Male & Female \\
\hline Language & English & Afrikaans & English & Afrikaans & English & Afrikaans \\
\hline $\begin{array}{l}\text { Oral-facial } \\
\text { examination }\end{array}$ & $\begin{array}{l}\text { General weakness. } \\
\text { Predominant lower } \\
\text { motor neuron } \\
\text { symptoms. Re- } \\
\text { duced oral reflexes }\end{array}$ & $\begin{array}{l}\text { Deviation of tongue to left. } \\
\text { Atrophy and fasciculations } \\
\text { of left side of tongue. Re- } \\
\text { duced range and rate of } \\
\text { tongue movement. }\end{array}$ & $\begin{array}{l}\text { Mild right-sided } \\
\text { facial and tongue } \\
\text { weakness. Involun- } \\
\text { tary grimacing and } \\
\text { spasms of the } \\
\text { face. Mouth } \\
\text { breathing. }\end{array}$ & $\begin{array}{l}\text { Normal symmetry. } \\
\text { Popping of TM } \\
\text { joint. Tremulous- } \\
\text { ness and mild de- } \\
\text { viation of tongue to } \\
\text { right. }\end{array}$ & $\begin{array}{l}\text { Right-sided facial } \\
\text { and tongue } \\
\text { weakness. Pop- } \\
\text { ping of TM joint. } \\
\text { Associated jaw } \\
\text { movements dur- } \\
\text { ing lateralization } \\
\text { of tongue. }\end{array}$ & $\begin{array}{l}\text { Rate of tongue } \\
\text { and lip move- } \\
\text { ments mildly } \\
\text { reduced. }\end{array}$ \\
\hline $\begin{array}{l}\text { Perceptual } \\
\text { characteristics }\end{array}$ & $\begin{array}{l}\text { Poor intelligibility. } \\
\text { Slowed, laboured } \\
\text { speech. Distorted } \\
\text { consonants and } \\
\text { vowels. Hyperna- } \\
\text { sal. Low-pitched, } \\
\text { harsh voice. Mono- } \\
\text { pitch and mono- } \\
\text { loudness. Pro- } \\
\text { longed phonemes. } \\
\text { Inappropriate si- } \\
\text { lences. }\end{array}$ & $\begin{array}{l}\text { Less dysarthric than FD1. } \\
\text { Imprecise lingual conso- } \\
\text { nants. Mild distortion of } \\
\text { velar consonants. Voice } \\
\text { soft and breathy. }\end{array}$ & $\begin{array}{l}\text { Reduced stress. } \\
\text { Accelerated, dys- } \\
\text { fluent speech. } \\
\text { Imprecise conso- } \\
\text { nants. Bilabial } \\
\text { plosives produced } \\
\text { as labiodental } \\
\text { fricatives. Mono- } \\
\text { pitch and mono- } \\
\text { loudness. Un- } \\
\text { steady, breathy } \\
\text { voice. Mild fluctuat- } \\
\text { ing nasality. }\end{array}$ & $\begin{array}{l}\text { Less dysarthric } \\
\text { than HD1. Mono- } \\
\text { pitch and mono- } \\
\text { loudness and re- } \\
\text { duced stress. } \\
\text { Breathy, tremulous } \\
\text { voice. Rapid rate. } \\
\text { Tendency to speak } \\
\text { on residual air. }\end{array}$ & $\begin{array}{l}\text { Slow rate. Harsh } \\
\text { vocal quality. } \\
\text { Periods of apho- } \\
\text { nia. Mono-pitch } \\
\text { and mono- } \\
\text { loudness. Ex- } \\
\text { cess and equal } \\
\text { stress. Imprecise } \\
\text { consonants. } \\
\text { Articulatory } \\
\text { breakdown. Fluc- } \\
\text { tuating nasality -- }\end{array}$ & $\begin{array}{l}\text { Less dysarthric } \\
\text { than AD1. } \\
\text { Excess and } \\
\text { equal stress. } \\
\text { Slow speech } \\
\text { rate. Prolonged } \\
\text { phonemes. } \\
\text { Consonant and } \\
\text { vowel distor- } \\
\text { tions. }\end{array}$ \\
\hline $\begin{array}{l}\text { Medication, } \\
\text { dosage and time } \\
\text { taken prior to } \\
\text { data collection }\end{array}$ & $\begin{array}{l}\text { Lanzor: } 15 \mathrm{mg} \text { daily } \\
\text { (mornings: } 1 \text { hour } \\
\text { before data collec- } \\
\text { tion) } \\
\text { Xanor: } 0.5 \mathrm{mg} \text { and } \\
\text { Cipramil } 20 \mathrm{mg} \\
\text { daily (evenings) }\end{array}$ & $\begin{array}{l}\text { Co-Diovan: } 80 \mathrm{mg} \text {, Lipitor: } \\
10 \mathrm{mg} \text { and Disprin: } 150 \mathrm{mg} \\
\text { daily (mornings: } 1 \text { hour } \\
\text { before data collection) } \\
\text { Diovan: } 80 \mathrm{mg}, \text { Aricpet: } 5 \text { - } \\
10 \mathrm{mg} \text { and Hytrin: } 5-10 \mathrm{mg} \\
\text { daily (evenings) }\end{array}$ & $\begin{array}{l}\text { Madopar: } \\
\text { (levadopa } 200 \mathrm{mg} \text {; } \\
\text { benserazide } \mathrm{HCl} \\
50 \mathrm{mg}) 1 / 2 \text { tablet } \\
\text { every two hours. } \\
\text { (Taken } 30 \text { minutes } \\
\text { before data collec- } \\
\text { tion) }\end{array}$ & $\begin{array}{l}\text { Sinemet: } 100 \mathrm{mg} 3 \mathrm{x} \\
\text { per day (Taken } 1 \\
\text { hour before data } \\
\text { collection) }\end{array}$ & None & None. \\
\hline
\end{tabular}




\section{Ethical considerations}

The study was cleared by the Faculty Research Proposal and Ethics Committee of the University of Pretoria. A letter explaining the aims and nature of the study was presented to the potential participants. This letter was supplemented with a verbal explanation of the nature of the study and the procedures involved in data collection. An informed consent form was attached to the letter. The participants were asked either to sign this form, or to give verbal consent if unable to sign due to motor involvement.

\section{Material used for data collection}

The test material consisted of 15 consonant-vowel-consonant (CVC) words embedded within the carrier phrase. 'It's a ....' for English and, 'Dit is ' $n$...' for Afrikaans to accommodate speakers of both languages. By matching the participants with control participants, the impact of possible differences in language was minimized to a large extent. Carrier phrases made it possible to elicit the target words in continuous speech while at the same time controlling the phonetic and phonological context. Each of the target words had either a voiceless bilabial, alveolar or velar stop consonant in word-initial position so that variability of the temporal parameters of VOT and VFTD could be determined. The vowels $/ \Lambda, \partial, \mathrm{i}, \varepsilon, æ, \mathrm{u}, \mathrm{o}$ and $\mathrm{a} /$ were included within the target words and represented the nucleus of the stressed syllable of the utterance. Each sentence was printed on white cardboard in size 22 font. The form in which these words were presented to each subject is presented in Table 2. The meaning of the Afrikaans words is indicated in brackets.

Table 2: Target phrases used in data collection

\begin{tabular}{|l|l|}
\hline \multicolumn{1}{|c|}{ English phrases } & \multicolumn{1}{|c|}{ Afrikaans phrases } \\
\hline It's a pet & Dit is 'n pet (It is a cap) \\
\hline It's a pit & Dit is 'n pit (It is a pip) \\
\hline It's a puck & Dit is 'n pak (It is a packet / suit) \\
\hline It's'a pup & Dit is pap (It is porridge) \\
\hline It's a putt & Dit is 'n pad (It is a road) \\
\hline It's a tack & Dit is 'n tek (short for technical college) \\
\hline It's a tick & Dit is 'n tiek (It is a tic) \\
\hline It's a tip & Dit is 'n tip (It is a tip) \\
\hline It's a top & Dit is 'n top (It is a top) \\
\hline It's a tuck & Dit is 'n tak (It is a branch) \\
\hline It's a cook & Dit is 'n koek (It is a cake) \\
\hline It's a cop & Dit is 'n kop (It is a head) \\
\hline It's a cuff & Dit is kaf (It is nonsense) \\
\hline It's a cup & Dit is 'n kap (It is a hood) \\
\hline It's a cut & Dit is 'n kat (It is a cat) \\
\hline
\end{tabular}

Apparatus used for data collection

A CP 430 Stereo Marantz tape recorder and an AKG D 1200 E short distance, directional microphone were used to record the speech of the subjects. TDK IEC 1 / TYPE 1 cassettes were used for the recordings.

\section{Apparatus used for data analysis}

The CP 430 Stereo Marantz tape recorder was used to send the speech signal to the Computerized Speech Laboratory (CSL 4300B) from the KAY Elemetrics Corporation. This signal was captured and analyzed by the digital signal processor. The speech signal was monitored with two JBL Pro 3 loudspeakers. The speech signal was presented on a NEC Multisync 2 display screen, where the time cursors and time axes were used to obtain the measurements on a dual display of soundwave and wideband spectrogram.

\section{Data collection procedures}

Recordings were made by the first author in a soundproof environment. The AKG D 1200 E short distance, directional microphone was positioned within $15 \mathrm{~cm}$ of the participant's mouth. The sentences were presented and read to the participants to familiarize them with the words and to answer any questions that they may have had. The participants were asked to read each sentence 10 times at a comfortable rate, pausing between repetitions so that the final energy of the target word did not run into the initial energy of the first word of the next sentence. The utterances were thus self-initiated and not imitated. Each sentence was held in front of the participant. The researcher counted the number of repetitions and indicated to the participant when ten repetitions were reached.

\section{Acoustic analysis procedures}

\section{Acoustic Analysis of Voice Onset Time}

Voice onset time (VOT) is defined as the interval between the release burst of the stop consonant and the appearance of periodic modulation for a following sound (Kent \& Read, 1992). VOT was thus measured from the start of the energy burst (indicating release of the stop closure) to the start of the first full glottal (periodic) pulse of the vowel of the target utterance. Forrest and Weismer (1997) define the first full glottal pulse of a vowel as showing energy through at least the first two formants.

\section{Acoustic Analysis of Vowel Formant Transition Duration}

Vowel formant transition duration (VFTD) was measured after VOT was measured. A formant transition is defined as the segment of the formant beginning at the burst release, and ending at the onset of the steady state portion of the vowel (Forrest $\&$ Weismer, 1997). In this study, the transition of the vowel formants was measured from the onset of the vowel to the steady state portion of the vowel. Only information pertaining to the vowel was obtained from this measurement. Thus, the term 'vowel formant transition duration' is used in this study, and not 'consonant-vowel transition duration'. Both Formant 1 (F1) and F2 were taken into consideration when measuring the VFTD. Specific attention was paid to F2 transitions, as this formant appears to be most sensitive to the changes in the shape of the vocal cavities (Gerratt, 1983). In certain cases where it was difficult to establish VFTD based on F1 and F2, F3 was considered as well.

\section{Acoustic Analysis of Vowel Steady State Duration}

Vowel steady state duration (VSSD) was measured from the end of the F1 and F2 transition to the onset of the VC-formant transition at the end of the target word. According to KewleyPort (1982), the onset of the steady state begins in that frame where frequency change falls to less than $10 \mathrm{~Hz}$ per 5 millisecond frame. 


\section{Acoustic Analysis of Vowel Duration}

Vowel duration (VD) was measured from the onset of the vowel, (from the first full glottal pulse) to the last full glottal pulse. This final glottal pulse showed periodic energy through the first and second formants as suggested by Forrest and Weismer (1997).

\section{Reliability and Validity}

To ensure reliability, $15 \%$ (every third repetition) of the data was re-analyzed by the first author. According to Seddoh et al. (1996), a difference of 3 msecs between the original value and the value obtained during the reliability check is considered reliable. In a study performed by Smith and Kenney (1994), an average difference of $4 \mathrm{msecs}$ (with a range of 2 msecs to. 10 msecs) was considered acceptable. In this study, a difference of 10 msecs or less was considered reliable for the durational measurements. A difference of 5 msecs or less was deemed reliable for the temporal parameter of VOT. The following formula was used to calculate the reliability of data analysis for each participant (Shriberg \& Kent, 1982):

\section{Percentage of amber of units scored similarly}

Overall, 93\% (range: $88 \%$ - 99\%) agreement was obtained. A researcher who has a master's degree in the field of acoustic analyses was consulted for assistance whenever problematic analyses arose and, in so doing, functioned as the second analyser.

Controlling the environment in which data collection took place enhanced the internal validity of the study. In addition, all possible factors, which may have influenced the results obtained (for example the use of medication by certain participants and the relative severity of the dysarthria), were taken into account in the interpretation of the results (Leedy \& Ormrod, 2005). Participants who were representative of individuals with ataxic, hypokinetic and flaccid dysarthria were selected ensure external validity of the study (Leedy \& Ormrod, 2005). Participant FD1 presented with a mixed form of dysarthira. However, he was selected to participate in this study, as his symptoms were predominantly flaccid in nature. Participant FDl was therefore considered representative of individuals with execution dysarthria.

\section{Data analysis procedures}

In this study, the degree of variability of speech, as well as the correlation between the durational parameters of speech were determined by means of descriptive statistics (Leedy \& Ormrod, 2005).

\section{Data Analysis Procedure for Sub-Aim 1}

The purpose of Sub-aim 1 was to determine the degree of variability of motor speech performance of the participants and their matched controls. A measure of dispersion, the coefficient of variation, was used to determine the degree of variability of each temporal parameter. The coefficient of variation, which is the standard deviation squared, is a dimensionless index, allowing measures of different sizes and units to be compared (Leedy, 1997; Leedy \& Ormrod, 2005). The coefficient of variation was calculated for each temporal parameter across the first nine repetitions of each of the 15 stimulus words produced by the participants and control participants. The tenth repetition of each stimulus word was omitted as most participants uttered the final repetition with greater emphasis as if to indicate that this was the final word of the series. This change in emphasis would not be representative of the former nine repetitions. The 15 coefficients of variation for each temporal parameter were then averaged for each participant and control participant. In this way, the overall degree of variability of speech was determined for each dysarthric participant and control participant. A comparison was then made of the overall degree of variability of speech between the dysarthric speakers and the control participants, and between the different types of dysarthria.

\section{Data Analysis Procedure for Sub-Aim 2}

The purpose of Sub-aim 2 was to determine the correlation between VD and VSSD, between VD and VFTD and between VSSD and VFTD across repeated production of the stimulus words by the participants. A Pearson product moment correlation (Leedy \& Ormrod, 2005) was applied to calculate the correlation coefficient between the durational parameters. Only the correlation between the durational parameters was calculated. The correlation coefficient was calculated for each durational parameter across all the words produced by the participants with dysarthria as well as their matched control participants. A comparison of the correlation between the durational parameters of the dysarthric speakers and the control participants, and between the different types of dysarthria was performed through subjective inspection of the data.

\section{RESULTS}

\section{Degree of variability of the temporal parameters}

The coefficients of variation calculated for each temporal parameter across repeated production of the 15 stimulus words are presented in Table 3 for each participant as well as each matched control participant.

As indicated in Table 3, all of the dysarthric speakers, excluding Participant FD2, exhibited greater variability of the temporal control of speech than their matched controls. Participant FD2 (who represented execution dysarthria), exhibited less variability than his matched control with regard to all the temporal parameters with the exception of VOT (28.13). Participant FD2 also exhibited the lowest degree of variability of VD (6.91) and VSSD (9.13) when compared with the other dysarthric speakers. In contrast to the relatively low degree of variability of

Table 3: Coefficients of variation of the temporal parameters of vowel duration, vowel steady state duration, vowel formant transition duration and voice onset time

\begin{tabular}{|l|l|l|l|l|l|l|l|l|l|l|l|l|}
\hline $\begin{array}{l}\text { Temporal } \\
\text { Parameters }\end{array}$ & FD1 & CFD1 & FD2 & CFD2 & HD1 & CHD1 & HD2 & CHD2 & AD1 & CAD1 & AD2 & CAD2 \\
\hline VD & 22.95 & 7.09 & 6.91 & 7.07 & 9.95 & 7.09 & 10.81 & 6.01 & 9.81 & 9.07 & 9.94 & 7.19 \\
\hline VSSD & 21.73 & 7.40 & 9.13 & 9.86 & 12.75 & 7.40 & 14.28 & 8.78 & $13.99^{\prime}$ & 10.04 & 10.47 & 9.73 \\
\hline VFTD & 39.38 & 21.37 & 28.58 & 29.07 & 41.77 & 21.37 & 29.99 & 27.72 & 37.60 & 36.97 & 28.35 & 29.06 \\
\hline VOT & 63.01 & 12.73 & 28.13 & 20.63 & 18.89 & 12.73 & 21.84 & 13.37 & 25.43 & 16.38 & 26.54 & 17.08 \\
\hline
\end{tabular}


the temporal control of speech exhibited by Participant FD2, Participant FD1 (who also represented execution dysarthria) showed the highest degree of variability for each of the temporal parameters, excluding VFTD when compared with the controls and the other dysarthric speakers. The possible influence of upper motor neuron involvement in Participant FD1 may have contributed to the high degrees of variability exhibited by this participant. Participant HDl exhibited the highest overall degree of variability of VFTD (41.77). From the information presented in Table 3 it would therefore appear that programming-execution dysarthria cannot be distinguished from execution dysarthria on the basis of the overall degree of variability of speech alone.

A comparison of the degree of intra-subject variability of each of the temporal parameters (Table 3) reveals differences in performance between the participants with programming-execution dysarthria and participants with execution dysarthria. For each of the control participants as well as the participants with programming-execution dysarthria, variability of VOT (which reflects interarticulatory synchronization) was greater than the durational parameters of VD and VSSD, but less variable than VFTD. The participants with programmingexecution dysarthria thus followed the same pattern of variability as the control participants with regard to intra-subject variability of the temporal parameters of speech. In contrast, Participant FDl (representing execution dysarthria), exhibited greater variability of VOT (63.01) than any of the durational parameters (VD: 22.95; VSSD: 21.73 and VFTD: 39.38). Participant FD2, who is considered to be a more true reflection of a lower motor neuron lesion than Participant FD1, obtained coefficients of variation of 28.13 for VOT and 28.58 for VFTD. Thus, while Participant FD2, like the other dysarthric speakers and control participants exhibited greater intra-subject variability of VFTD than VOT, the difference in variability was not as great. In summary, it would appear that the participants with programming-execution dysarthria followed the same pattern of variability as the control participants with regard to the intrasubject variability of the temporal parameters, while the participants with execution dysarthria did not.

\section{Correlation between durational parameters}

The averages of the correlation coefficients between the durational parameters of VD, VSSD and VFTD exhibited by each participant and control participant across repeated production of the stimulus word are indicated in Table 4.

According to the information presented in Table 4, each of the dysarthric speakers achieved the highest correlation between the durational parameters of VD and VSSD. Thus, for each of the dysarthric speakers, an increase in milliseconds of VD was accompanied by a concomitant increase in milliseconds of VSSD. The same appears to be true for each of the control participants with the exception of CAD2 who achieved a higher correlation coefficient $(0.43)$ between VD and VFTD than between VD and VSSD $(0,40)$. Furthermore, for each of the dysarthric speakers, as well as their matched control participants, the correlation between VD and VFTD was also positive. Finally, the lowest correlation exhibited by each of the dysarthric speakers as well as their matched controls was found between VSSD and VFTD. It would thus appear that each of the dysarthric speakers followed the same trends as the normal speakers with regard to the nature of the correlations between the durational parameters. It was therefore not possible to differentiate between programming-execution dysarthria and execution dysarthria based on the nature of the correlation between the durational parameters.

\section{DISCUSSION}

\section{Variability of temporal parameters}

The results regarding the degree of variability of the temporal control of speech revealed that each of the dysarthric speakers, with the exception of participant FD2, exhibited greater variability than the control participants. Participant FD2 exhibited less variability of vowel duration, vowel steady state duration and vowel formant transition duration, but greater variability of voice onset time than his matched control participant. The finding that the dysarthric speakers were more variable than the controls is in agreement with previous research investigating variability of dysarthric speech. For example, increased variability of vowel durations in individuals with ALS has been reported (Turner \& Tjaden, 2000; Weismer, Tjaden \& Kent, 1996). Increased variability of motor speech performance in hypokinetic dysarthria associated with Parkinson's Disease (Reed \& Franks, 1998) as well as in ataxic dysarthria (Hertrich \& Ackermann, 1999) has also been reported. If temporal variability of speech is indeed an indication of the precision or reliability of motor control (Kent et al., 1991), then it is to be expected that dysarthric speakers would show greater variability of the temporal control of speech than the control participants. All the dysarthric speakers, with the exception of participant FD2 (excluding voice onset time) confirmed this prediction. However, it was not possible, in this study, to differentiate programming-execution dysarthria from execution dysarthria on the basis of the overall degree of variability of speech. For example, in contrast to the relatively low degrees of variability exhibited by Participant FD2, Participant FD1 (representing the same dysarthria group as Participant FD2) exhibited the highest overall degree of variability of vowel duration, vowel steady state duration and voice onset time. The possibility exists that variables such as age, medication, the presence of involuntary movements (Gerratt, 1983), speech rate (Kent et al., 1991; McHenry, 2003) and the severity of dysarthria (Kent et al., 1979; McHenry, 2003) contribute in a particular way to the overall degree of variability exhibited by dysarthric speakers. Differences due to these factors thus complicate the differentiation between the levels of breakdown in dysarthria.

Table 4: Correlation coefficients between the durational parameters of vowel duration, vowel teady state duration and vowel formant transition duration

\begin{tabular}{|c|c|c|c|c|c|c|c|c|c|c|c|c|}
\hline & FD1 & CFD1 & FD2 & CFD2 & HD1 & CHD1 & HD2 & CHD2 & AD1 & CAD1 & AD2 & CAD2 \\
\hline $\begin{array}{l}\text { Correlation between VD } \\
\text { and VSSD }\end{array}$ & 0.76 & 0.82 & 0.69 & 0.80 & 0.85 & 0.82 & 0.70 & 0.88 & 0.80 & 0.73 & 0.80 & 0.40 \\
\hline $\begin{array}{l}\text { Correlation between VD } \\
\text { and VFTD }\end{array}$ & 0.64 & 0.79 & 0.47 & 0.24 & 0.29 & 0.79 & 0.60 & 0.44 & 0.4 & 0.22 & 0.37 & 0.43 \\
\hline $\begin{array}{l}\text { Correlation between } \\
\text { VSSD and VFTD }\end{array}$ & 0.32 & 0.48 & 0.12 & -0.26 & -0.06 & 0.48 & 0.25 & 0.31 & 0.00 & -0.04 & 0.15 & -0.07 \\
\hline
\end{tabular}


A comparison of the temporal parameters showing the highest degrees of variability revealed differences between programming-execution dysarthria and execution dysarthria. For each of the dysarthric speakers as well as each of the control speakers, voice onset time was more variable than vowel duration and vowel steady state duration, but less variable than vowel formant transition duration. In contrast, Participant FD1 (representing execution dysarthria) exhibited greatest variability of voice onset time. Similarly, Participant FD2 (also representing execution dysarthria) showed relatively high degrees of intra-subject variability of VOT when compared with the other temporal parameters. It would therefore appear that the individuals with programming-execution dysarthria followed the same patterns of variability as the control participants, despite showing a higher overall degree of variability of motor speech control. The individuals with execution dysarthria, on the other hand, do not appear to have followed the same trends as the normal speakers or the participants from the programmingexecution dysarthria group with regard to intra-subject variability of the temporal parameters.

The similar performance of the individuals with programming-execution dysarthria to that of the control participants regarding intra-subject variability of the temporal parameters may be explained by the possibility of the participants with hypokinetic dysarthria and ataxic dysarthria resorting to employing cortical mechanisms to control motor performance (Brooks, 1986). While this is likely to take longer and movements are likely to be executed less automatically, the possible cortical control over movements in individuals with basal ganglia or cerebellar involvement may reflect greater movement control than that seen in an individual with flaccid dysarthria who has intact motor planning and motor programming abilities, but an inability to execute movements according to the specifications of these plans and programmes due to impaired lower motor neurons (Von Gruenewaldt, 2003).

The relatively high degrees of intra-subject variability of voice onset time exhibited by Participants FD1 and FD2 may be interpreted within the context of the FLF (Van der Merwe, 1997; 2007). Voice onset time reflects inter-articulatory synchronization (Van der Merwe, 1997) and assesses the temporal coordination of the vocal folds and the oral articulators. According to the FLF (Van der Merwe, 1997; 2007), the potential for inter-articulatory synchronization is created on the motor planning level of the speech production process. If this is true, then Participants FD1 and FD2 (each representing execution dysarthria) possess the potential to plan the synchronization between the oral and laryngeal articulators for voice onset time. In addition, they possess the ability to specify motor programmes for the muscles of the necessary articulators. However, the coordinated execution of the movements of the articulators according to the specifications of the motor plan and programme is likely to be impaired in these speakers. The degree to which the execution of movements required for voice onset time is impaired, is likely to be related to the extent to which the motor neurons are impaired. The finding that Participant FD2 was less variable with regard to voice onset time than Participant FD1 may therefore be because Participant FD2 only needed to coordinate weak tongue and velar movements with intact laryngeal articulators. In ALS, the articulatory structures are not all affected to the same degree (DePaul \& Brooks, 1993). The coordinated execution of movements of the oral and laryngeal articulators was thus likely to have been more difficult for Participant FD1.

In summary, each of the dysarthric speakers, with the exception of Participant FD2 (excluding voice onset time), ex- hibited greater overall variability of the temporal control of speech than their matched control participants. The individuals with programming-execution dysarthria followed similar patterns of variability to the control group. In contrast, the participants with execution dysarthria differed with regard to the pattern of variability exhibited when compared with the participants with programming-execution dysarthria and the control group. This is a possible indication that individuals with programming-execution dysarthria resort to a different level of control than individuals with execution dysarthria.

\section{Interactive control of durational parameters}

The results of the correlation analysis showed that all the participants (with the exception of CAD2) achieved the highest correlation between the durational parameters of vowel duration and vowel steady state duration. The correlation between vowel duration and vowel formant transition duration was also positive (again, with the exception of CAD2). For each of the participants, the lowest correlation was found between vowel steady state duration and vowel formant transition duration. In summary, the general trend of the current research results suggests that the dysarthric speakers performed in a similar way to the control participants with regard to the nature of the correlation between the durational parameters. The implication of these results is that the dysarthric speakers, regardless of factors such as the degree of variability of motor speech performance, age, medication, the presence of involuntary movements, speech rate, and severity of dysarthria, were able to maintain the internal timing relations between the durational parameters.

The positive correlation between vowel duration and vowel steady state duration and between vowel duration and vowel formant transition duration exhibited by the control participants is not unexpected. Given that there can be considerable changes in absolute duration and magnitude of individual muscle events, there must be some stability in the internal relations between muscle events that underlie the phonetic percept (Harris et al., 1986). Thus, for many skilled activities, it is the internal timing relations that are preserved over such transformations as rate and force changes.

The reason for the ability of the dysarthric speakers to maintain the internal timing relation between the durational parameters is unclear. In addition, there is no existing data with which the correlation coefficients reported in this study may be compared. The possibility exists that, despite the higher degrees of variability of the individual temporal parameters exhibited by the dysarthric speakers (with the exception of FD2) when compared with the control participants, the dysarthric speakers may have been able to consciously control the relative duration of the movements executed, thereby preserving the perceptual identity of the words produced. Alternatively, the dysarthric speakers may have implemented compensatory techniques to preserve the perceptual identity of words. For example, individuals with ALS exhibit consistently greater weakness in the tongue as compared to the jaw and lower lip (DePaul \& Brooks, 1993). Increasing the range of jaw opening (particularly during the production of vowels) is seen to be a strategy to compensate for reduced tongue movement (DePaul \& Brooks, 1993; Turner \& Tjaden, 2000) and is achieved by adjusting the motor programmes of the muscles of the jaw. If this is the case, the jaw may become the primary articulator in an individual with ALS, resulting in the jaw, lower lip and tongue moving together as a single mass. If this is so, then one could expect to see a linear relationship between vowel duration and vowel steady state duration and between vowel steady 
state duration and vowel formant transition duration in a speaker with ALS.

Whatever the reason may be for the maintenance of the internal timing relations between the durational parameters by the dysarthric speakers, it was not possible, on the basis of the correlation analysis, to differentiate between programming-execution dysarthria and execution dysarthria. It was also not possible, however, to differentiate the dysarthric speakers from the normal speakers on the basis of the correlation analysis. The internal timing relations between the durational parameters of words may therefore not be a sensitive index of pathology. Additional indeces of variability which may further explore the hypothesis set by the FLF (Van der Merwe, 1997; 2007), namely that programming-execution dysarthria differs from execution dysarthria must be investigated.

\section{CONCLUSION}

This study was a preliminary exploration of the variability of motor speech performance of individuals with flaccid dysarthria, hypokinetic dysarthria and ataxic dysarthria in an attempt to differentiate between programming-execution dysarthria and execution dysarthria. The FLF (Van der Merwe, 1997; 2007) was used as the conceptual framework for this study. The degree of variability of motor speech performance, and the correlations between the durational parameters of speech were investigated as possible indeces to differentiate between the dysarthria types.

The dysarthric speakers performed in a similar way to the control participants regarding the correlations between the durational parameters. It was therefore neither possible to differentiate between the control participants and the dysarthric speakers, nor between the participants with programming-execution dysarthria and the participants with execution dysarthria, on the basis of the correlation analysis. Investigation of correlation between the durational parameters may therefore not have been an accurate index to pathology.

Examination of the degree of variability of the temporal parameters of speech showed that the participants with hypokinetic and ataxic dysarthria (representing programming-execution dysarthria) exhibited the same patterns of variability as the controls regarding intrasubject variability of the temporal parameters. In contrast, the participants representing execution dysarthria exhibited relatively higher degrees of intra-subject variability of voice onset time. These differences found in the patterns of variability support the hypothesis presented by the FLF (Van der Merwe, 1997; 2007), that individuals with programming-execution dysarthria resort to a different level of control than those with execution dysarthria. It is recommended that more extensive research be performed on the variability of motor speech performance normal speakers. In addition, it is recommended that future research investigating variability of motor speech performance in dysarthria be performed using larger speaker groups in which speakers are matched for severity of dysarthria. Additional indeces of variability should be explored to further investigate the hypotheses set by the FLF (Van der Merwe, 1997; 2007).

\section{REFERENCES}

Ballard, K.J., Granier, J.P., \& Robin, D.A. (2000). Understanding the nature of apraxia of speech: Theory, analysis and treatment. Aphasiology, 14 (10), 969-995.

Brooks, V.B. (1986). The Neural Basis of Motor Control. New York: Oxford University Press.

Darley, F.L., Aronson, A.E., \& Brown, J.R. (1975). Motor Speech Disorders. Philadelphia: W. B Saunders Company.

Duffy, J.R. (2005). Motor Speech Disorders: Substrates, Differential Diagnosis and Management $\left(2^{\text {nd }}\right.$ ed.). St Louis: Mosby.

Duffy, J.R., \& Kent, R.D. (2001). Darley's contributions to the understanding, differential diagnosis, and scientific study of the dysarthrias. Aphasiology, 15 (3), 275-289.

DePaul, R., \& Brooks, B.R. (1993). Multiple orofacial indeces in Amyotrophic Lateral Sclerosis. Journal of Speech and Hearing Research, 36, 1158-1167.

Forrest, K., \& Weismer, G. (1997). Acoustic analysis of dysarthric speech. In M.R. McNeil (Ed.). Clinical Management of Sensorimotor Speech Disorders. New York: Thieme Medical Publishers.

Gerratt, B.R. (1983). Formant frequency fluctuation as an index of motor steadiness in the vocal tract. Journal of Speech and Hearing Research, 26, 297-304.

Hageman, C. (1997). Flaccid dysarthria. In M.R. McNeil (Ed.). Clinical Management of Sensorimotor Speech Disorders. New York: Thieme Medical Publishers.

Harris, K.S., Tuller, B., \& Kelso, J.A.S. (1986). Temporal invariance in the production of speech. In J.S. Perkell \& D.H. Klatt (Eds.). Invariance and Variability in Speech Processes. New Jersey: Lawrence Erlbaum Associate Publishers.

Hertrich, l. \& Ackermann, H. (1999). Temporal and spectral aspects of coarticulation in ataxic dysarthria: An acoustic analysis. Journal of Speech, Language and Hearing Research, 42, 367-381

Hixon, T.J., Putnam, A.H.B., \& Sharp, J.T. (1983). Speech production with flaccid paralysis of the rib-cage, diaphragm and abdomen. Journal of Speech and Hearing Disorders, $48,315-327$

Itoh, M. \& Sasanuma, S. (1984). Articulatory movements in apraxia of speech. In J.C. Rosenbek, M.R. McNeil \& A.E. Aronson (Eds.). Apraxia of Speech: Physiology, Acoustics, Linguistics and Management. San Diego: College-Hill Press.

Kent, R.D., Netsell, R., \& Abbs, J.H. (1991). Acoustic characteristics of dysarthria associated with cerebellar disease. In R.J Baken \& R.G. Daniloff (Eds.). Readings in Clinical Spectography of Speech. New Jersey: Singular Publishing Group Inc.

Kent, R.D., \& Read, C. (1992). The Acoustic Analysis of Speech. San Diego: Singular Publishing Group.

Kewly-Port, D. (1982). Measurement of formant transitions in naturally produced stop consonant-vowel syllables. Journal of the Acoustical Society of America, 72 (2), 379389

Leedy, P.D. (1997). Practical Research: Planning \& Design. $\left(6^{\text {th }}\right.$ Ed.). New Jersey: Prentice Hall.

Leedy, P. D. \& Ormrod, J. E. (2005). Practical Research: Planning and Design (8 Ed.).New Jersey: Pearson Merrill Prentice Hall.

Levelt, W. J. M. (1989). Speaking: From Intention to Articulation. Cambridge: The MIT Press.

Magill, R. A. (2007). Molor Learning and Control: Concepts and Applications ( $8^{\text {th }}$ Ed.). Bosion: McGraw Hill.

McHenry, M.A. (2003). The effect of pacing strategies on the variability of speech movement sequences in dysarthria. Journal of Speech, Language and Hearing Research, $46,702-710$.

McHenry, M.A. (2004). Variability within and across physiological systems in dysarthria: A comparison of STI and VOT. Journal of Medical Speech-Language Pathology, 12 (4), $179-182$

Munhall, K.G. (1989). Articulatory variability. In P. Square-Storer (Ed.). Acquired Apraxia of Speech in Aphasic Adulls: Theoretical and Clinical lssues. Hove and London: Lawrence Erlbaum Associates, Publishers. 
Pols, L.C.W. (1986). Variation and interaction in speech. In J.S. Perkell \& D.H. Klatt (Eds.). Invariance and variability in Speech Processes. New Jersey: Lawrence Erlbaum Associates, Publishers.

Reed, C.L. \& Franks, I.M. (1998). Evidence of movement preprogramming and on-line control in differently impaired patients with Parkinson's Disease. Cognitive Neuropsychology, 15 (6/7/8), 723745.

Seddoh, S.A.K., Robin, D.A., Sim, H.-S., Hageman, C., Moon, J.B., \& Folkins, J.W. (1996). Speech timing in apraxia of speech versus conduction aphasia. Journal of Speech and Hearing Research, 39, 590603 .

Shriberg, L.D., \& Kent, R.D. (1982). Clinical Phonetics. New York: John Wiley \& Sons.

Smith, B.L., \& Kenney, M.K. (1994). Variability control in speech production tasks performed by adults and children. Journal of the Acoustical Society of America, 96 (2), 699-705.
Tumer, G.S., \& Tjaden, K. (2000). Acoustic differences between content and function words in Amyotrophic Lateral Sclerosis. Journal of Speech, Language and Hearing Research, 43 (3), 796-815.

Van der Merwe, A. (1997). A theoretical framework for the characterization of pathological speech sensorimotor control. In M.R. McNeil (Ed.). Clinical Management of Sensorimotor Speech Disorders. New York: Thieme Medical Publishers.

Van der Merwe, A. (In press). A theoretical framework for the characterization of pathological speech sensorimotor control. In M.R. McNeil (Ed.). Clinical Management of Sensorimotor Speech Disorders ( $2^{\text {nd }}$ ed.). New York: Thieme Medical Publishers.

Von Gruenewaldt, A.M. (2003). Acquired dysarthria within the context of the fourlevel framework of speech sensorimotor control. Unpublished Masters minidissertation, University of Pretoria, South Africa.

Weismer, G. Tjaden, K. \& Kent, R.D (1995). Can articulatory behaviour in motor speech disorders be accounted for by theories of normal speech production? Journal of Phonetics, 23, 149-164. 